\title{
Email Patient-Provider Communication and Cancer Screenings Among US Adults: Cross-sectional Study
}

Tiffany B Kindratt ${ }^{1}$, MPH, PhD; Marlyn Allicock ${ }^{2,3}, \mathrm{MPH}, \mathrm{PhD}$; Folefac Atem ${ }^{4}$, PhD; Florence J Dallo ${ }^{5}, \mathrm{MPH}, \mathrm{PhD}$; Bijal A Balasubramanian ${ }^{3,6}$, MBBS, MPH, PhD

\footnotetext{
${ }^{1}$ Public Health Program, Department of Kinesiology, College of Nursing and Health Innovation, University of Texas at Arlington, Arlington, TX, United States

${ }^{2}$ Department of Health Promotion and Behavioral Sciences, School of Public Health Dallas, UTHealth, The University of Texas Health Science Center at Houston, Dallas, TX, United States

${ }^{3}$ Center for Health Promotion and Prevention Research, Harold C. Simmons Comprehensive Cancer Center, University of Texas Southwestern Medical Center, Dallas, TX, United States

${ }^{4}$ Department of Biostatistics and Data Science, School of Public Health Dallas, UTHealth, The University of Texas Health Science Center at Houston, Dallas, TX, United States

${ }^{5}$ Department of Public and Environmental Wellness, School of Health Sciences, Oakland University, Rochester, MI, United States

${ }^{6}$ Department of Epidemiology, Human Genetics, and Environmental Health Sciences, School of Public Health Dallas, UTHealth, The University of Texas Health Science Center at Houston, Dallas, TX, United States
}

\section{Corresponding Author:}

Tiffany B Kindratt, MPH, PhD

Public Health Program, Department of Kinesiology

College of Nursing and Health Innovation

University of Texas at Arlington

500 W. Nedderman Drive

Arlington, TX, 75919

United States

Phone: 118179389223

Email: tiffany.kindratt@uta.edu

\section{Abstract}

Background: The growth of electronic medical records and use of patient portals have allowed for patients and health care providers to communicate via email and direct messaging between health care visits. Email patient-provider communication (PPC) may enhance traditional face-to-face PPC by allowing patients to ask questions, receive clear explanations, engage in shared decision-making, and confirm their understanding between in-person visits. Despite increasing trends in the use of email PPC since the early 2000s, few studies have evaluated associations between email PPC and the uptake of preventive services.

Objective: The objective of this study was to determine associations between the use of email PPC and the likelihood of undergoing breast, cervical, and colon cancer screenings among adults who have received health care in the past 12 months.

Methods: Secondary, cross-sectional data from the 2011-2015 National Health Interview Survey were combined and analyzed. For each cancer screening, inclusion criteria were based on the age of screening recommendations and prior history of cancer diagnosis ( $n=35,912$ for breast, $n=48,512$ for cervical, and $n=45,884$ for colon). The independent variable was whether adults used email PPC in the past 12 months (yes or no). The dependent variables were whether (1) women (aged $\geq 40$ years) received a mammogram in the past 12 months; (2) women (aged 21-65 years) received a Pap test in the past 12 months; and (3) individuals (aged $\geq 50$ years) received a colon cancer screening in the past 12 months. Bivariate and multivariable logistic regression analyses were conducted.

Results: Adults who reported receiving all three cancer screenings in the past 12 months were more likely to be non-Hispanic White; be married or living with a partner; have a bachelor's degree or higher education level; have health insurance coverage; and perceive their health as excellent, very good, or good (all $P<.001$ ). Men were more likely to receive colon cancer screenings than women $(P<.001)$. Multivariable logistic regression models showed women who used email to communicate with their health care providers had greater odds of receiving breast (odds ratio [OR] 1.32, 95\% CI 1.20-1.44) and cervical (OR 1.11, 95\% CI 1.02-1.20) cancer screenings than women who did not use email PPC. Adults who used email to communicate with their health 
care providers had 1.55 times greater odds (95\% CI 1.42-1.69) of receiving a colon cancer screening than those who did not use email PPC.

Conclusions: Our results demonstrate that email PPC is a marker of increased likelihood of adults completing age-appropriate cancer screenings, particularly breast, cervical, and colon cancer screenings. More research is needed to examine other factors related to the reasons for and quality of email PPC between patients and health care providers and determine avenues for health education and intervention to further explore this association.

(JMIR Cancer 2021;7(3):e23790) doi: 10.2196/23790

\section{KEYWORDS}

email; patient-provider communication; online, patient portals; mammogram; Pap test; colon cancer screening; cancer screenings; National Health Interview Survey

\section{Introduction}

Email patient-provider communication (PPC) is broadly defined to include computer-based PPC "within a contractual relationship in which the health care provider has taken an active measure of responsibility for the clients" [1]. Email PPC includes messages sent through electronic personal health management tools and patient portals, which can enhance traditional face-to-face communication between health care providers and patients. Email PPC has been used by patients for asynchronous inquiries about nonacute issues, medication information, administration questions, and lab results [2]. Adults who used email PPC reported it was most useful for managing appointments, asking administrative questions, reviewing test results, requesting prescriptive refills, and asking health-related questions [2,3]. Individuals have also reported benefits of email PPC for communicating sensitive issues that patients may be too embarrassed to discuss during face-to-face encounters and follow-up visits for chronic diseases [4]. Although some studies have demonstrated that email PPC can increase the quality and efficiency of health care delivery [5], others have found that the use of electronic and email PPC, and the use of "e-visits," may lead to more office visits and limit health care providers' abilities to treat new patients [6]. Despite patients expressing interest in communicating with their provider via email, the uptake remains low [2]. In 2003, only $4 \%$ of adults reported using email to communicate with their health care provider. By 2018, the prevalence of email PPC had increased to $36 \%$ [7]. Among older adults, its prevalence rose from $2.7 \%$ in 2009 to $14.2 \%$ in 2018 [8]. Regardless of increasing trends, email PPC remains underutilized, and disparities exist based on demographic, socioeconomic, and health-related characteristics [7,9-12]. Previous studies have found that adults who engage in email PPC are more likely to be female and younger aged; living in urban areas; have higher levels of education and income; and have a history of chronic disease [7,9-11]. Several studies have found that non-Hispanic White adults are more likely to use email PPC than non-Hispanic Black and Hispanic adults [4], yet the usage of email PCC among Hispanic adults varies by US- and foreign-born subgroups [12]. These differences may be due to structural barriers that exist with broadband internet access, which may be more limited in poor neighborhoods [13]. Individuals with diabetes, cardiovascular disease, hypertension, a history of cancer, and multiple chronic conditions are more likely to use email PPC than adults with no chronic diseases $[10,11]$. Other studies have demonstrated that gay and bisexual men are more likely to use email PPC than heterosexual men [14].

Although previous research has demonstrated that quality face-to-face PPC during traditional visits is a marker of an increased likelihood of adults receiving cancer screenings and immunizations [15-20], few studies have evaluated the impact of email PPC between visits on the individual's use of preventive services. Interventions using electronic patient health records and patient portals that engage patients in taking an active role in their health care through electronic means have been effective at improving delivery of recommended cancer screenings [21]. However, less is known about how this engagement through electronic modes of communication with providers between visits can improve cancer screening outcomes. Huang and colleagues [22] demonstrated that adults who used patient portals to schedule appointments, request referrals or prescription refills, share medical records, or communicate with health care professionals by email were more likely to receive a blood pressure check, lipid level check, influenza vaccination, or colon cancer screening than those who did not use patient portals. Totzkay and colleagues [23] found that women who used electronic medical records were more likely to receive breast cancer screenings. Despite positive findings, these studies did not directly evaluate associations between email PPC and likelihood of adults receiving immunizations and cancer screenings.

To begin to fill this gap in our understanding of how email PPC may be a marker of increased likelihood of cancer screenings, this study is part of a program of research that utilizes national health surveys to examine how predisposing and enabling factors are associated with morbidity, mortality, and use of health services. Patient experiences, including the use of face-to-face, email, and other electronic communications with health care providers, are examined as enabling factors of health services use as an extension of Anderson's Behavioral Model of Health Services [24]. Two preliminary studies were conducted to determine whether email PPC is a marker of increased likelihood of vaccinations and cancer screenings. Using cross-sectional data from the National Health Interview Survey (NHIS), we found that adults who used email PPC had greater odds of reporting receipt of an influenza vaccine [25]. Using cross-sectional data from the Health Information National Trends Survey (HINTS), we found no difference in the odds of reporting receipt of breast, cervical, or colon cancer screening among adults who used email PPC compared to those who did 
not use email PPC [15]. Although nationally representative, the HINTS sample is much smaller (ie, $\mathrm{N}=3865$ adults in HINTS 5 Cycle 3 ) than the NHIS sample (ie, $\mathrm{N}=31,997$ adults in 2019), and the focus of the survey content is geared toward cancer risk communication [26,27]. More research is needed to confirm these findings by using larger nationally representative samples focused on broader topics of morbidity, mortality, and the use of preventive services. To further explore this relation, this study aimed to determine the association between email PPC use and the likelihood of adults receiving breast, cervical, and colon cancer screenings before and after controlling for potential covariates.

\section{Methods}

\section{Data Source}

We analyzed secondary, cross-sectional data from the 2011-2015 NHIS. Since 1957, the NHIS has collected information on demographics, socioeconomics, and a wide range of health topics among the civilian noninstitutionalized US population [28]. During 2011-2015, the NHIS used a multistage sampling design to monitor national trends in health, illness, and disability while tracking progress toward national goals by using a computer-assisted personal interviewing system during face-to-face interviews [28]. The sampling design oversampled Hispanic, Asian, and non-Hispanic Black persons to increase the precision of estimates among racial and ethnic minorities [28]. Information about health information technology use and cancer screening behaviors have been measured annually since 2011 [29-31]. Further details of the NHIS sampling design and data collection methods have been reported previously [28].

\section{Participants}

We limited our sample to individuals who received primary health care in the past 12 months and were within the recommended age groups for each cancer screening of interest. For breast cancer screening, for instance, our sample was limited to women aged 40 years and above without any prior history of breast cancer based on American College of Obstetricians and Gynecologists (ACOG) screening recommendations $(n=35,912)$ [32]. For cervical cancer screenings, our sample was limited to women aged 21-65 years without any prior history of cervical cancer based on the American Cancer Society (ACS), ACOG, and the United States Preventive Services Task Force (USPSTF) screening recommendations $(n=48,512)$ [33-35]. For colon cancer screenings, our sample was limited to adults aged 50 years and older without any prior history of colon cancer based on the ACS screening recommendations $(n=45,884)$ [33]. Individuals who reported that they do not use the internet were excluded.

\section{Variables}

\section{Independent Variable}

The NHIS measured email PPC by asking individuals, "During the past 12 months, have you ever used computers for any of the following," specifically to "...communicate with a health care provider by email" (yes or no question) [28].

\section{Dependent Variables}

For breast cancer screenings, the NHIS asked women aged 30 years and older, "Have you had a mammogram during the past 12 months?" For cervical cancer screenings, women aged 18 years and older were asked, "Have you had a pap smear or pap test during the past 12 months?" Adults aged 40 years and older were asked, "During the past 12 months, have you had any test done for colon cancer [28]?" Dichotomous variables (yes or no) were created for each screening measure based on the abovementioned inclusion criteria for age.

\section{Covariates}

We evaluated the following covariates based on previous studies [15,25]: age (ie, 21-29 years and 30-39 years for cervical cancer screenings only, 40-49 years for breast and cervical cancer screenings only, 50-59 years, 60-70 years [60-65 years for cervical cancer screenings], or 70 years and older); sex (ie, female or male); race or ethnicity (ie, non-Hispanic White, Hispanic, non-Hispanic Black, or non-Hispanic "other" race); nativity status (born in the United States or not born in the United States); marital status (ie, never married; married or living as married; divorced, widowed, or separated); highest level of education achieved (ie, no degree, high school degree or General Educational Development tests, some college or associate degree, or bachelor's degree or higher); insurance coverage (ie, insured or uninsured); perceived health status (ie, excellent, very good, or good vs fair or poor); and survey year.

\section{Statistical Analysis}

Bivariate analyses were used to describe the association between demographic, socioeconomic, health-related characteristics, use of email PPC, and receipt of each cancer screening in the past 12 months (chi-square test; =.05). We calculated age-adjusted prevalence estimates of receiving breast, cervical, and colon cancer screenings among adults who reported using email PPC by using estimated marginal (least-squares) means. Crude and multivariable logistic regression procedures were used to test for associations between email PPC (independent variable) and whether they received breast, cervical, and colon cancer screenings (dependent variable) before and after controlling for covariates. Purposeful selection methods were used for building fitted multivariable logistic regression models [36]. Our multivariable models were adjusted for age (reference: youngest age group, 40-49 years for breast cancer screenings, 21-30 years for cervical cancer screenings, and 50-59 years for colon cancer screenings); race or ethnicity (reference: non-Hispanic White); marital status (reference: never married); education (reference: bachelor's degree or higher); health insurance (reference: covered); and perceived health status (reference: fair or poor). For colon cancer screenings only, multivariable models were adjusted for sex (reference: men).

\section{Sensitivity Analysis}

Sensitivity analyses were conducted to align with different age cutoffs for screening recommendations from other agencies based on previous research [37]. For breast cancer and colon cancer screenings, we limited the sample to women aged 50-75 years based on USPSTF recommendations [37,38]. No 
sensitivity analyses were conducted for cervical cancer screenings.

Data were analyzed using SAS software (version 9.4) survey procedures to account for primary sampling units, clustering, and the sophisticated weighting in the sampling design. The annual sample adult weight was divided by five to account for combining 5 years of data based on NHIS analytic recommendations [39].

This study was deemed exempt from human subjects review by the Committee for the Protection of Human Subjects at the University of Texas Health Science Center at Houston.

\section{Results}

\section{Selected Characteristics}

The mean ages of women who received breast and cervical cancer screenings in the past 12 months were 56.90 years $(95 \%$ CI 56.71-57.08) and 41.2 (95\% CI 41.00-41.40) years, respectively. The mean age of adults who received a colon cancer screening the past 12 months was 62.1 (95\% CI 61.94-62.35) years. Women who reported having a breast cancer screening in the past 12 months were more likely to be
non-Hispanic White; be married or living with a partner; have a bachelor's degree or higher level of education; have health insurance coverage; and perceive their health as excellent, very good, or good (all $P<.05$ ). Similar results were observed for cervical cancer screenings. Additionally, US-born women $(27,006 / 31,977,85.5 \%$ weighted) were more likely to receive a cervical cancer screening than foreign-born women (4971/31,977, 14.5\% weighted; $P<.001)$. Furthermore, over half $(5587 / 11,713,50.9 \%$ weighted $)$ of the adults who received a colon cancer screening were male $(P<.001)$. Results were similar to those for breast and cervical cancer screenings for race or ethnicity, marital status, education, and health insurance coverage (all $P<.001$ ). Further details of the bivariate analyses (unweighted frequencies and weighted percentages) are reported in Table 1.

Age-adjusted prevalence estimates of receiving a breast, cervical, or colon cancer screening based on email PPC use are reported in Table 2. Among adults who received primary health care in the last 12 months, the age-adjusted prevalence of receiving a colon cancer screening was the lowest $(34.4 \%)$ among those who used email PPC compared to women who underwent breast $(70.5 \%)$ and cervical (70.6\%) cancer screenings. 
Table 1. Selected characteristics by receiving a breast, cervical and colon cancer screening in the last 12 months, National Health Interview Survey 2011-2015.

\begin{tabular}{|c|c|c|c|c|c|c|c|c|c|}
\hline \multirow[t]{2}{*}{ Characteristic } & \multicolumn{3}{|c|}{$\begin{array}{l}\text { Breast cancer screening }(\mathrm{n}=35,912), \mathrm{n} \\
\text { (weighted \%) }\end{array}$} & \multicolumn{3}{|c|}{$\begin{array}{l}\text { Cervical cancer screening }(\mathrm{n}=48,512), \mathrm{n} \\
\text { (weighted \%) }\end{array}$} & \multicolumn{3}{|c|}{$\begin{array}{l}\text { Colon cancer screening }(\mathrm{n}=45,884), \mathrm{n} \\
\text { (weighted \%) }\end{array}$} \\
\hline & $\begin{array}{l}\text { No } \\
(n=13,557)\end{array}$ & $\begin{array}{l}\text { Yes } \\
(n=22,355)\end{array}$ & $P$ value & $\begin{array}{l}\text { No } \\
(n=16,530)\end{array}$ & $\begin{array}{l}\text { Yes } \\
(n=31,982)\end{array}$ & $P$ value & $\begin{array}{l}\text { No } \\
(n=34,171)\end{array}$ & $\begin{array}{l}\text { Yes } \\
(n=11,713)\end{array}$ & $P$ value \\
\hline Race or ethnicity & & & .005 & & & $<.001$ & & & $<.001$ \\
\hline $\begin{array}{l}\text { Non-Hispanic } \\
\text { White }\end{array}$ & 9659 (76.3) & $\begin{array}{l}15,865 \\
(76.4)\end{array}$ & & $\begin{array}{l}11,087 \\
(72.0)\end{array}$ & $\begin{array}{l}19,598 \\
(68.7)\end{array}$ & & $\begin{array}{l}26,330 \\
(81.6)\end{array}$ & 8476 (78.5) & \\
\hline Hispanic & $1367(8.4)$ & 2200 (7.9) & & 2175 (11.3) & 4801 (11.9) & & $2494(6.1)$ & $950(6.4)$ & \\
\hline $\begin{array}{l}\text { Non-Hispanic } \\
\text { Black }\end{array}$ & $1752(9.6)$ & $3121(10.6)$ & & $2013(9.5)$ & 5493 (13.6) & & $3646(7.6)$ & $1698(10.5)$ & \\
\hline $\begin{array}{l}\text { Non-Hispanic } \\
\text { Asian or Other }\end{array}$ & $779(5.7)$ & $1169(5.0)$ & & $1255(7.1)$ & $2090(5.8)$ & & $1701(4.7)$ & $589(4.6)$ & \\
\hline Nativity status & & & .46 & & & .001 & & & 0.03 \\
\hline Foreign-born & $1856(13.9)$ & 3089 (13.5) & & 2649 (15.9) & $4971(14.5)$ & & 3895 (11.5) & 1431 (12.6) & \\
\hline US-born & $\begin{array}{l}11,697 \\
(86.1)\end{array}$ & $\begin{array}{l}19,263 \\
(86.5)\end{array}$ & & $\begin{array}{l}13,875 \\
(84.1)\end{array}$ & $\begin{array}{l}27,006 \\
(85.5)\end{array}$ & & $\begin{array}{l}30,269 \\
(88.5)\end{array}$ & $\begin{array}{l}10,279 \\
(87.4)\end{array}$ & \\
\hline Marital status & & & $<.001$ & & & $<.001$ & & & $<.001$ \\
\hline Never married & $1502(8.1)$ & $2165(6.6)$ & & 3498 (18.2) & 7557 (18.5) & & $2963(5.9)$ & $949(5.5)$ & \\
\hline $\begin{array}{l}\text { Married or living } \\
\text { with partner }\end{array}$ & $6340(61.1)$ & $\begin{array}{l}12,227 \\
(69.2)\end{array}$ & & 8752 (63.6) & $\begin{array}{l}17,838 \\
(67.5)\end{array}$ & & $\begin{array}{l}18,594 \\
(69.3)\end{array}$ & $6792(72.5)$ & \\
\hline $\begin{array}{l}\text { Divorced, wid- } \\
\text { owed, or separat- } \\
\text { ed }\end{array}$ & $5664(30.8)$ & $7899(24.2)$ & & 4232 (18.2) & $6507(14.1)$ & & $\begin{array}{l}12,522 \\
(24.8)\end{array}$ & 3947 (22.0) & \\
\hline Education & & & $<.001$ & & & $<.001$ & & & $<.001$ \\
\hline $\begin{array}{l}\text { Less than high- } \\
\text { school graduate }\end{array}$ & $1426(9.1)$ & $1515(5.6)$ & & $1352(7.5)$ & $2076(5.4)$ & & $2989(7.3)$ & $955(6.8)$ & \\
\hline $\begin{array}{l}\text { High-school } \\
\text { graduate }\end{array}$ & $3360(25.2)$ & $4857(22.2)$ & & $3598(22.5)$ & $5724(18.1)$ & & 8134 (24.0) & 2468 (20.9) & \\
\hline Some college & 4758 (34.7) & 7325 (31.8) & & $6136(36.9)$ & $\begin{array}{l}11,050 \\
(33.8)\end{array}$ & & $\begin{array}{l}10,822 \\
(30.9)\end{array}$ & 3808 (31.7) & \\
\hline $\begin{array}{l}\text { Bachelor's de- } \\
\text { gree or higher }\end{array}$ & 3966 (31.0) & $8600(40.3)$ & & $5400(33.2)$ & $\begin{array}{l}13,081 \\
(42.8)\end{array}$ & & $\begin{array}{l}12,127 \\
(37.8)\end{array}$ & 4447 (40.6) & \\
\hline Health insurance & & & $<.001$ & & & $<.001$ & & & $<.001$ \\
\hline Not covered & $1506(11.0)$ & $865(3.5)$ & & 2391 (13.7) & $2989(8.0)$ & & $1882(5.1)$ & $302(2.4)$ & \\
\hline Covered & $\begin{array}{l}12,016 \\
(89.0)\end{array}$ & $\begin{array}{l}21,446 \\
(96.5)\end{array}$ & & $\begin{array}{l}14,078 \\
(86.3)\end{array}$ & $\begin{array}{l}28,915 \\
(92.0)\end{array}$ & & $\begin{array}{l}32,223 \\
(94.9)\end{array}$ & $\begin{array}{l}11,396 \\
(97.6)\end{array}$ & \\
\hline Perceived health statu & & & $<.001$ & & & $<.001$ & & & .08 \\
\hline Fair or poor & $2760(18.5)$ & $2736(11.0)$ & & $2694(15.0)$ & $2806(7.7)$ & & $5765(15.3)$ & $2105(16.1)$ & \\
\hline $\begin{array}{l}\text { Excellent, very } \\
\text { good, or good }\end{array}$ & $\begin{array}{l}10,792 \\
(81.5)\end{array}$ & $\begin{array}{l}19,606 \\
(89.0)\end{array}$ & & $\begin{array}{l}13,831 \\
(85.0)\end{array}$ & $\begin{array}{l}29,162 \\
(92.3)\end{array}$ & & $\begin{array}{l}28,385 \\
(84.7)\end{array}$ & $9606(83.9)$ & \\
\hline Survey year & & & $<.001$ & & & $<.001$ & & & 0.02 \\
\hline 2011 & $3875(27.9)$ & $5414(23.8)$ & & $3493(21.2)$ & $7455(23.0)$ & & 9299 (26.6) & $3139(25.8)$ & \\
\hline 2012 & $1991(15.2)$ & $3872(17.7)$ & & $2683(16.3)$ & $6222(18.9)$ & & $5259(16.0)$ & $1889(16.3)$ & \\
\hline 2013 & $2323(17.5)$ & $4168(19.1)$ & & $3175(19.4)$ & $6219(19.6)$ & & $5899(17.8)$ & $2159(19.5)$ & \\
\hline 2014 & 2675 (18.9) & 4554 (19.4) & & $3645(21.0)$ & $6319(18.9)$ & & $6901(19.3)$ & $2260(18.3)$ & \\
\hline 2015 & 2693 (20.4) & 4347 (19.9) & & $3534(22.1)$ & 5767 (19.5) & & 6813 (20.4) & $2266(20.1)$ & \\
\hline
\end{tabular}


Table 2. Age-adjusted prevalence of screenings by email patient-provider communication (PPC), National Health Interview Survey 2011-2015.

\begin{tabular}{llll}
\hline Email PPC & Breast cancer screening, OR $^{\mathrm{a}}(95 \% \mathrm{CI})$ & Cervical cancer screening, OR (95\% CI) & Colorectal cancer screening, OR (95\% CI) \\
\hline No & $62(61-63)$ & $67(66-67)$ & $25(24-26)$ \\
Yes & $71(69-72)$ & $71(69-72)$ & $34(33-36)$ \\
\hline
\end{tabular}

${ }^{\mathrm{a} O R}$ : odds ratio.

\section{Logistic Regression Analysis}

Crude and adjusted logistic regression results are reported in Table 3. In adjusted models, women who used email to communicate with their health care providers had 1.32 times greater odds (95\% CI 1.20-1.44) of receiving a breast cancer screening and 1.11 times greater odds (95\% CI 1.02-1.20) of receiving a cervical cancer screening than women who did not use email PPC. Adults who used email to communicate with their health care providers had 1.55 times greater odds $(95 \% \mathrm{CI}$ 1.42-1.69) of receiving a colon cancer screening than those who did not use email PPC. Specific estimates for covariates included in our logistic regression models are provided in Table $\mathrm{S} 1$ of Multimedia Appendix 1

Table 3. Crude and adjusted logistic regression models, National Health Interview Survey 2011-2015.

\begin{tabular}{|c|c|c|c|c|c|c|}
\hline \multirow[t]{2}{*}{ Email PPC } & \multicolumn{2}{|c|}{ Breast cancer screening ${ }^{\mathrm{b}}, \mathrm{OR}^{\mathrm{c}}(95 \% \mathrm{CI})$} & \multicolumn{2}{|c|}{ Cervical cancer screening ${ }^{\mathrm{b}}$, OR $(95 \% \mathrm{CI})$} & \multicolumn{2}{|c|}{ Colorectal cancer screening ${ }^{\mathrm{b}}, \mathrm{OR}(95 \% \mathrm{CI})$} \\
\hline & Crude & Adjusted & Crude & Adjusted & Crude & Adjusted \\
\hline No & 1.00 & 1.00 & 1.00 & 1.00 & 1.00 & 1.00 \\
\hline Yes & $1.50(1.38,1.62)$ & $1.32(1.20,1.44)$ & $1.17(1.08,1.27)$ & $1.11(1.02,1.20)$ & $1.58(1.44,1.73)$ & $1.55(1.42,1.69)$ \\
\hline
\end{tabular}

${ }^{\mathrm{a}} \mathrm{PPC}$ : patient-provider communication.

${ }^{\mathrm{b}}$ For each cancer screening, multivariable models adjusted for age (reference: youngest age group, 40-49 years for breast cancer screening, 21-30 years for cervical cancer screening, 50-59 years for colon cancer screening); race or ethnicity (reference: non-Hispanic White); marital status (reference: never married); education (reference: bachelor's degree or higher); health insurance (reference: covered); and perceived health status (reference: fair or poor). For colon cancer screening only, multivariable models adjusted for sex (reference: men).

${ }^{\mathrm{c}} \mathrm{OR}$ : odds ratio.

\section{Sensitivity Analysis}

Crude and adjusted logistic regression results from our sensitivity analysis are reported in Table S2 of Multimedia Appendix 1. The results were similar to our analytical sample. All 95\% CIs overlapped with our initial findings.

\section{Discussion}

\section{Principal Findings}

We aimed to determine the association between email PPC and whether adults received breast, cervical, and colon cancer screenings. Overall, we found that adults who used email to communicate with their health care providers between visits had greater odds of receiving each of the three types of screenings. These findings go beyond our previous research that used other nationally representative data sources (Medical Expenditure Panel Survey and HINTS), which demonstrated that quality face-to-face PPC increased the likelihood of adults receiving cancer screenings $[15,16]$. Nevertheless, there was no difference in breast, cervical, or colon cancer screening uptake among adults who did and those who did not use email PPC.

Using the NHIS, we were able to further explore the role of email PPC as a marker of the likelihood of adults receiving cancer screening using a nationally representative sample larger than that used in previous studies. For breast cancer screening, we found that women who used email PPC had $32 \%$ increased odds of receiving a mammogram compared to women who did not use email PPC. Other studies exploring whether online PPC and general health information technology use were associated with breast cancer screening found that electronic medical record and patient portal use increased women's likelihood of receiving mammograms [23,40-42]. Moreover, we found that email PPC increased women's odds of receiving a Pap test by $11 \%$. This finding result differs from our study using HINTS data, which did not find any association between email PPC and cervical cancer screenings [15]. To our knowledge, only one other study has demonstrated that general electronic medical record use can increase cervical cancer screenings [41]. Finally, we found that the use of email PPC increased the likelihood of adults receiving a colon cancer screening by $55 \%$. Our previous study using HINTS data indicated that adults had 39\% higher odds of receiving a colon cancer screening; however, the results did not reach statistical significance (95\% CI 0.99-1.95). Similar to studies evaluating breast cancer screening, previous research has demonstrated that adults who used patient portals to schedule appointments, request referrals or prescription refills, view decision aids, share medical records, or communicate with health care professionals by email were more likely to receive colon cancer screenings than those who did not use patient portals $[22,42]$. For all cancer screenings, the lack of research providing direct comparisons to our results may be due to limitations of examining email PPC only, which excludes other online communicative functions such as text messaging, mobile apps, and social media [43].

For all cancer screenings, several factors may have contributed to obtaining results different from our previous study using 
HINTS data [15]. The greatest factor may be the way email PPC was measured. The NHIS measured whether adults used computers or the internet to communicate with their health care provider by email [28]. A similar measure was used in the HINTS 4 survey during Cycles 1 and 3 [44]. Adults who responded "yes" on either survey may have regarded automatic emails for appointment reminders or diagnostic test results as email PPC versus directly emailing their health care provider about specific health concerns. During HINTS Cycle 3 and 4, this question was revised to directly assess whether adults exchanged health information with their health care provider via email [44]. The reasoning for and quality of communication remained unmeasured by both surveys. Future iterations of these data sources should be revised to fully capture communication behaviors to further explore the implications of email PPC on the uptake of preventive services.

\section{Strengths and Limitations}

A strength of this study was the use of survey data from multiple years of the NHIS, a nationally representative survey that has consistently measured health behaviors, preventive health services, and a wide array of other health-related characteristics to meet national health objectives for over 60 years [28]. The depth and breadth of demographic, socioeconomic, and health-related characteristics measured by the NHIS on an annual basis allowed us to explore and control for multiple covariates in our logistic regression models. However, the NHIS does not collect characteristics on patient engagement in health care outside from assessing adults' use of health information technology to look up health information, refill prescriptions, schedule appointments, use online chat groups, and communicate with health care providers via email that may result in unresolved confounding. Previous research has demonstrated that adults who use electronic methods of communication with their health care providers and adults who follow recommended cancer screening guidelines are more engaged in their health care than those who do not [5]. In our study, email PPC and cancer screening behaviors were both measured in the past 12 months based on how the questions were asked by the NHIS. Our results may suffer from temporality biases, as we were unable to determine whether email PPC occurred before or after receiving any cancer screening. By limiting our cancer screening outcome to the past 12 months instead of based on adherence (eg, past 2 years for mammogram, past 3 years for Pap testing, and past 10 years for colonoscopy), we minimized this potential bias. A limitation to our measurement of email PPC was that we were unable to determine the direction of the email (ie, patient to provider vs provider to patient) and whether the content of the communication was screening related or pertaining to any medical information. The clinical significance of our results may be limited due to reporting odds ratios and marginal means. The use of other marginal effects may have improved our study's practical relevance [45]. Our cancer screening measures were self-reported. Some studies have cautioned that results from self-reported nationally representative studies may overestimate cancer screening uptake [46], whereas others have found that self-reported responses are consistent with findings from hospital records $[47,48]$. It is also important to note that the NHIS is a cross-sectional survey, so our results only represent associations instead of causal relations.

\section{Conclusions}

This study begins to fill the gap in our understanding of how email PPC and direct electronic messaging between appointments may be a marker of the increased likelihood of adults receiving preventive health services, in particular, cancer screening uptake. More research is needed to determine the need for and effectiveness of targeted strategies for promoting appropriately timed cancer screenings by using web-based PPC tools such as email and direct messaging. Furthermore, there is a need for more research to examine reasons for and quality of email PPC for making preventive health care decisions.

\section{Conflicts of Interest}

None declared.

\section{Multimedia Appendix 1}

Supplementary tables presenting results from logistic regression models. [DOCX File , 36 KB-Multimedia Appendix 1]

\section{References}

1. Kane B, Sands DZ. Guidelines for the clinical use of electronic mail with patients. The AMIA Internet Working Group, Task Force on Guidelines for the Use of Clinic-Patient Electronic Mail. J Am Med Inform Assoc 1998;5(1):104-111 [FREE Full text] [doi: 10.1136/jamia.1998.0050104] [Medline: 9452989]

2. Ye J, Rust G, Fry-Johnson Y, Strothers H. E-mail in patient-provider communication: a systematic review. Patient Educ Couns 2010 Aug;80(2):266-273 [FREE Full text] [doi: 10.1016/j.pec.2009.09.038] [Medline: 19914022]

3. Haun JN, Patel NR, Lind JD, Antinori N. Large-scale survey findings inform patients' experiences in using secure messaging to engage in patient-provider communication and self-care management: a quantitative assessment. J Med Internet Res 2015 Dec 21;17(12):e282 [FREE Full text] [doi: 10.2196/jmir.5152] [Medline: 26690761]

4. Atherton H, Sawmynaden P, Sheikh A, Majeed A, Car J. Email for clinical communication between patients/caregivers and healthcare professionals. Cochrane Database Syst Rev 2012 Nov 14;11:CD007978. [doi: 10.1002/14651858.CD007978.pub2] [Medline: 23152249] 
5. Antoun J. Electronic mail communication between physicians and patients: a review of challenges and opportunities. Fam Pract 2016 Apr;33(2):121-126. [doi: 10.1093/fampra/cmv101] [Medline: 26711957]

6. Bavafa H, Hitt LM, Terwiesch C. The impact of e-visits on visit frequencies and patient health: evidence from primary care. Manage Sci 2018 Dec;64(12):5461-5480 [FREE Full text] [doi: 10.1287/mnsc.2017.2900] [Medline: 33033417]

7. Senft N, Butler E, Everson J. Growing disparities in patient-provider messaging: trend analysis before and after supportive policy. J Med Internet Res 2019 Oct 07;21(10):e14976 [FREE Full text] [doi: 10.2196/14976] [Medline: 31593539]

8. Hung L, Lyons JG, Wu C. Health information technology use among older adults in the United States, 2009-2018. Curr Med Res Opin 2020 May;36(5):789-797. [doi: 10.1080/03007995.2020.1734782] [Medline: 32096650]

9. Tarver WL, Menser T, Hesse BW, Johnson TJ, Beckjord E, Ford EW, et al. Growth dynamics of patient-provider internet communication: trend analysis using the Health Information National Trends Survey (2003 to 2013). J Med Internet Res 2018 Mar 29;20(3):e109 [FREE Full text] [doi: 10.2196/jmir.7851] [Medline: 29599107]

10. Asan O, Cooper Ii F, Nagavally S, Walker RJ, Williams JS, Ozieh MN, et al. Preferences for health information technologies among us adults: analysis of the Health Information National Trends Survey. J Med Internet Res 2018 Oct 18;20(10):e277 [FREE Full text] [doi: 10.2196/jmir.9436] [Medline: 30341048]

11. Zhang Y, Lauche R, Sibbritt D, Olaniran B, Cook R, Adams J. Comparison of health information technology use between American adults with and without chronic health conditions: findings from the National Health Interview Survey 2012. J Med Internet Res 2017 Oct 05;19(10):e335 [FREE Full text] [doi: 10.2196/jmir.6989] [Medline: 28982644]

12. Gonzalez M, Sanders-Jackson A, Wright T. Web-based health information technology: access among Latinos varies by subgroup affiliation. J Med Internet Res 2019 Apr 16;21(4):e10389 [FREE Full text] [doi: 10.2196/10389] [Medline: $\underline{30990462]}$

13. Perzynski AT, Roach MJ, Shick S, Callahan B, Gunzler D, Cebul R, et al. Patient portals and broadband internet inequality. J Am Med Inform Assoc 2017 Sep 01;24(5):927-932 [FREE Full text] [doi: 10.1093/jamia/ocx020] [Medline: 28371853]

14. Dahlhamer JM, Galinsky AM, Joestl SS, Ward BW. sexual orientation and health information technology use: a nationally representative study of U.S. adults. LGBT Health 2017 Apr;4(2):121-129 [FREE Full text] [doi: 10.1089/1gbt.2016.0199] [Medline: 28287875]

15. Kindratt T, Atem F, Dallo F, Allicock M, Balasubramanian B. The influence of patient-provider communication on cancer screening. J Patient Exp 2020 Dec;7(6):1648-1657 [FREE Full text] [doi: 10.1177/23743373520924993] [Medline: 33457626]

16. Kindratt TB, Dallo FJ, Allicock M, Atem F, Balasubramanian BA. The influence of patient-provider communication on cancer screenings differs among racial and ethnic groups. Prev Med Rep 2020 Jun;18:101086 [FREE Full text] [doi: 10.1016/j.pmedr.2020.101086] [Medline: 32309115]

17. Villani J, Mortensen K. Patient-provider communication and timely receipt of preventive services. Prev Med 2013 Nov;57(5):658-663. [doi: 10.1016/j.ypmed.2013.08.034] [Medline: 24021993]

18. Carcaise-Edinboro P, Bradley CJ. Influence of patient-provider communication on colorectal cancer screening. Med Care 2008 Jul;46(7):738-745. [doi: 10.1097/MLR.0b013e318178935a] [Medline: 18580394]

19. Underhill ML, Kiviniemi MT. The association of perceived provider-patient communication and relationship quality with colorectal cancer screening. Health Educ Behav 2012 Oct;39(5):555-563 [FREE Full text] [doi: 10.1177/1090198111421800] [Medline: 21986241]

20. Ho MY, Lai JY, Cheung WY. The influence of physicians on colorectal cancer screening behavior. Cancer Causes Control 2011 Dec;22(12):1659-1668. [doi: 10.1007/s10552-011-9842-4] [Medline: 21971815]

21. Krist AH, Woolf SH, Rothemich SF, Johnson RE, Peele JE, Cunningham TD, et al. Interactive preventive health record to enhance delivery of recommended care: a randomized trial. Ann Fam Med 2012;10(4):312-319 [FREE Full text] [doi: 10.1370/afm.1383] [Medline: 22778119]

22. Huang J, Chen Y, Landis JR, Mahoney KB. Difference between users and nonusers of a patient portal in health behaviors and outcomes: retrospective cohort study. J Med Internet Res 2019 Oct 07;21(10):e13146 [FREE Full text] [doi: 10.2196/13146] [Medline: 31593546$]$

23. Totzkay D, Silk KJ, Sheff SE. The effect of electronic health record use and patient-centered communication on cancer screening behavior: an analysis of the Health Information National Trends Survey. J Health Commun 2017 Jul;22(7):554-561. [doi: 10.1080/10810730.2017.1338801] [Medline: 28682179]

24. Andersen RM. National health surveys and the behavioral model of health services use. Med Care 2008 Jul;46(7):647-653. [doi: 10.1097/MLR.0b013e31817a835d] [Medline: 18580382]

25. Kindratt T, Callender L, Cobbaert M, Wondrack J, Bandiera F, Salvo D. Health information technology use and influenza vaccine uptake among US adults. Int J Med Inform 2019 Sep;129:37-42. [doi: 10.1016/j.ijmedinf.2019.05.025] [Medline: $\underline{31445279]}$

26. Health Information National Trends Survey, Public Use Dataset. National Cancer Institute. URL: https://hints.cancer.gov/ data/download-data.aspx [accessed 2021-04-09]

27. National Health Interview Survey, 2019. Centers for Disease Control and Prevention. URL: https://www.cdc.gov/nchs/ nhis/2019nhis.htm [accessed 2021-04-09] 
28. National Health Interview Survey - NHIS Data, Questionnaires and Related Documentation. National Center for Health Statistics, Centers for Disease Control and Prevention. URL: https://www.cdc.gov/nchs/nhis/ data-questionnaires-documentation.htm [accessed 2020-08-23]

29. Sandefer RH, Khairat SS, Pieczkiewicz DS, Speedie SM. Using publicly available data to characterize consumers use of email to communicate with healthcare providers. Stud Health Technol Inform 2015;216:401-405. [Medline: 26262080]

30. Cohen RA, Adams PF. Use of the internet for health information: United States, 2009. NCHS Data Brief 2011 Jul(66):1-8 [FREE Full text] [Medline: 22142942]

31. Bhandari N, Shi Y, Jung K. Seeking health information online: does limited healthcare access matter? J Am Med Inform Assoc 2014;21(6):1113-1117 [FREE Full text] [doi: 10.1136/amiajnl-2013-002350] [Medline: 24948558]

32. Practice Bulletin Number 179: breast cancer risk assessment and screening in average-risk women. Obstet Gynecol 2017 Jul;130(1):e1-e16. [doi: 10.1097/AOG.0000000000002158] [Medline: 28644335]

33. Smith RA, Andrews KS, Brooks D, Fedewa SA, Manassaram-Baptiste D, Saslow D, et al. Cancer screening in the United States, 2017: a review of current American Cancer Society guidelines and current issues in cancer screening. CA Cancer J Clin 2017 Mar;67(2):100-121 [FREE Full text] [doi: 10.3322/caac.21392] [Medline: 28170086]

34. Practice Bulletin No. 168: cervical cancer screening and prevention. Obstet Gynecol 2016 Oct;128(4):e111-e130. [doi: 10.1097/AOG.0000000000001708] [Medline: 27661651]

35. US Preventive Services Task Force, Curry SJ, Krist AH, Owens DK, Barry MJ, Caughey AB, et al. Screening for cervical cancer: US Preventive Services Task Force recommendation statement. JAMA 2018 Aug 21;320(7):674-686. [doi: 10.1001/jama.2018.10897] [Medline: 30140884$]$

36. Hosmer DW, Lemeshow S, Sturdivant RX. Applied Logistic Regression, 3rd Edition. Hoboken, NJ: John Wiley \& Sons, Inc; 2013.

37. Siu AL, U.S. Preventive Services Task Force. Screening for breast cancer: U.S. Preventive Services Task Force recommendation statement. Ann Intern Med 2016 Feb 16;164(4):279-296 [FREE Full text] [doi: 10.7326/M15-2886] [Medline: 26757170]

38. US Preventive Services Task Force, Bibbins-Domingo K, Grossman DC, Curry SJ, Davidson KW, Epling JW, et al. Screening for colorectal cancer: US Preventive Services Task Force recommendation statement. JAMA 2016 Jun 21;315(23):2564-2575. [doi: 10.1001/jama.2016.5989] [Medline: 27304597]

39. Variance Estimation Guidance, NHIS 2006-2015. 2016 Jun 13. URL: https://www.cdc.gov/nchs/data/nhis/2006var.pdf [accessed 2020-08-23]

40. Henry SL, Shen E, Ahuja A, Gould MK, Kanter MH. The online personal action plan: a tool to transform patient-enabled preventive and chronic care. Am J Prev Med 2016 Jul;51(1):71-77. [doi: 10.1016/j.amepre.2015.11.014] [Medline: 26826751]

41. Thompson CA, Gomez SL, Chan A, Chan JK, McClellan SR, Chung S, et al. Patient and provider characteristics associated with colorectal, breast, and cervical cancer screening among Asian Americans. Cancer Epidemiol Biomarkers Prev 2014 Nov;23(11):2208-2217 [FREE Full text] [doi: 10.1158/1055-9965.EPI-14-0487] [Medline: 25368396]

42. Krist AH, Woolf SH, Hochheimer C, Sabo RT, Kashiri P, Jones RM, et al. Harnessing information technology to inform patients facing routine decisions: cancer screening as a test case. Ann Fam Med 2017 May;15(3):217-224 [FREE Full text] [doi: 10.1370/afm.2063] [Medline: 28483886]

43. Jiang S, Street RL. Factors influencing communication with doctors via the internet: a cross-sectional analysis of 2014 HINTS Survey. Health Commun 2017 Feb;32(2):180-188. [doi: 10.1080/10410236.2015.1110867] [Medline: 27196037]

44. Survey Instruments - Health Information National Trends Survey. National Cancer Institute. URL: https://hints.cancer.gov/ data/survey-instruments.aspx [accessed 2020-08-23]

45. Norton EC, Dowd BE, Maciejewski ML. Marginal effects-quantifying the effect of changes in risk factors in logistic regression models. JAMA 2019 Apr 02;321(13):1304-1305. [doi: 10.1001/jama.2019.1954] [Medline: 30848814]

46. Rauscher GH, Johnson TP, Cho YI, Walk JA. Accuracy of self-reported cancer-screening histories: a meta-analysis. Cancer Epidemiol Biomarkers Prev 2008 Apr;17(4):748-757 [FREE Full text] [doi: 10.1158/1055-9965.EPI-07-2629] [Medline: 18381468]

47. Barratt A, Cockburn J, Smith D, Redman S. Reliability and validity of women's recall of mammographic screening. Aust N Z J Public Health 2000 Feb;24(1):79-81. [doi: 10.1111/j.1467-842x.2000.tb00728.x] [Medline: 10777984]

48. King ES, Rimer BK, Trock B, Balshem A, Engstrom P. How valid are mammography self-reports? Am J Public Health 1990 Nov;80(11):1386-1388. [doi: 10.2105/ajph.80.11.1386] [Medline: 2240315]

\section{Abbreviations}

ACS: American Cancer Society

ACOG: American College of Obstetricians and Gynecologists

HINTS: Health Information National Trends Survey

NHIS: National Health Interview Survey

OR: odds ratio

PPC: patient-provider communication 
USPSTF: United States Preventive Services Task Force

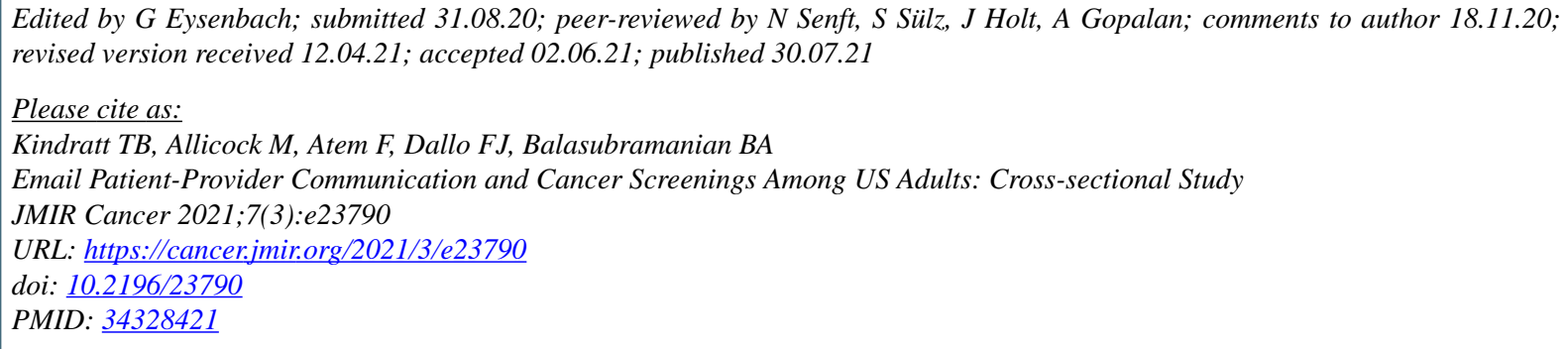

(C) Tiffany B Kindratt, Marlyn Allicock, Folefac Atem, Florence J Dallo, Bijal A Balasubramanian. Originally published in JMIR Cancer (https://cancer.jmir.org), 30.07.2021. This is an open-access article distributed under the terms of the Creative Commons Attribution License (https://creativecommons.org/licenses/by/4.0/), which permits unrestricted use, distribution, and reproduction in any medium, provided the original work, first published in JMIR Cancer, is properly cited. The complete bibliographic information, a link to the original publication on https://cancer.jmir.org/, as well as this copyright and license information must be included. 